\title{
Contribuições da psicologia para a relação professor-aluno
}

\author{
Alexandra Coelho Pena \\ Pontificia Universidade Católica do Rio de Janeiro, Rio de Janeiro, RJ, Brasil
}

\begin{abstract}
Resumo
As concepções de diferentes abordagens da psicologia - e de outros campos de saber - sobre como o ser humano conhece podem contribuir para a compreensão da relação que se estabelece entre adultos e crianças, adultos e adolescentes e adultos e adultos nos diversos segmentos educacionais, da creche à universidade. Trata-se de artigo de revisão de literatura que tem por objetivo explicitar os principais conceitos das teorias de Jean Piaget, Lev Vigotski, Wilhelm Reich e Martin Buber, buscando com isso elementos que ajudem na compreensão da complexa relação professor-aluno, que vai além da sala de aula, rompendo com uma concepção de ensino como transferência de conhecimento. Essa relação se constrói em um determinado tempo e espaço, marcados por valores, ideologias, normas e discursos. As contribuições da psicologia para a educação devem caminhar no sentido de ajudar a compreender as complexas interações que se estabelecem no interior das instituições educativas, contextualizando os fenômenos e abordando-os no âmbito das relações entre as pessoas, considerando a complexidade que envolve essa discussão.
\end{abstract}

Palavras-chave: psicologia; educação; relação professor-aluno.

\section{Contributions of psychology to the teacher-student relationship}

\begin{abstract}
The views of different approaches of psychology - and of other fields of knowledge-about the way human being acquires knowledge, may contribute to the comprehension of the relation that is established between adults and kids, adults and teenager and adults and adults in the many educational segments, from day care to university. The goal of the article is to explain the main concepts of theories of Jean Piaget, Lev Vigotski, Wilhelm Reich and Martin Buber, seeking with this, elements that help in the comprehension of the complex teacher-student relationship that goes beyond the classroom and disrupting with a view of education as transfer of knowledge. This relationship is built in a given time and space, marked by values, ideologies, norms and discourses. The contributions of psychology to education must move towards helping to understand the complex interactions established within educational institutions, contextualizing the phenomena and addressing them in the context of relationships between people, considering the complexity involved in this discussion.
\end{abstract}

Keywords: psychology; education; teacher-student relationship.

\section{Contribuciones de la psicología a la relación maestro-estudiante}

\section{Resumen}

Concepciones de diferentes enfoques de la psicología - y otras áreas del conocimiento - acerca de cómo el ser humano conoce, pueden contribuir a la comprensión de la relación que se establece entre adultos y niños, adultos y adolescentes y adultos y adultos en los diferentes segmentos educativos, desde la guardería a la universidad. Se trata de un artículo de revisión de la literatura cuyo objetivo es explicar los principales conceptos de las teorias de Jean Piaget, Lev Vigotski, Wilhelm Reich y Martin Buber, buscando elementos que contribuyan a la comprensión de la compleja relación profesor-alumno, que va más allá de la clase, rompiendo con una concepción de la enseñanza como transferencia de conocimiento. Esa relación se construye en un tiempo y un espacio determinados, marcados por valores, ideologías, normas y discursos. Las contribuiciones de la psicología a la educación deben ayudar a comprender las complejas interacciones que se establecen al interior de las instituciones educativas, contextualizando los fenómenos en el ámbito de las relaciones entre las personas, considerando la complejidad que involucra esa discusión.

Palabras clave: psicología; educación; relación maestro-estudiante.

\section{Introdução}

Falar sobre a relação professor-aluno, que é um aspecto fundamental do processo educativo, é refletir sobre o contexto da escola, lugar de produção de conhecimento, e considerar os aspectos que podem constituir essa relação. Portanto, as concepções de diferentes abordagens da psicologia - e de outros campos de saber - sobre como o ser humano conhece, podem contribuir para a compreensão da relação que se estabelece entre professores e alunos nos diversos segmentos educacionais, da creche à universidade.

\footnotetext{
^Endereço para correspondência: Pontifícia Universidade Católica do Rio de Janeiro. Rua Marquês de São Vicente, 225, Gávea - Rio de Janeiro, RJ - Brasil CEP: 22451-900.E-mail: alexandracpena@gmail.com

Os dados completos da autora encontram-se ao final do artigo.
}

Quatro pensadores nascidos no final do século XIX são trazidos para essa discussão: Piaget, Vigotski, Wilhelm Reich e Buber. Inseridos em contextos diversos e situados em diferentes campos epistemológicos, eles têm em comum a ruptura com uma concepção de ensino como transferência de conhecimento. Eles apostam em uma aprendizagem que é construída por professores e alunos, em que nem um nem outro se reduzem à condição de objeto, já que, como diz Paulo Freire (2013), não há docência sem discência.

Piaget e Vigotski são referências para o campo da Psicologia da Educação, e suas teorias têm dado suporte a inúmeras pesquisas acadêmicas e práticas pedagógicas. Ambos tinham interesse na origem e no 
processo do conhecimento humano e, em certo sentido, podemos dizer que os dois são construtivistas, no sentido epistemológico, pois para eles o conhecimento se constrói processualmente, embora cada um tenha uma visão distinta de como isso acontece. Assim, se para Piaget (1959) é o desenvolvimento que determina a aprendizagem e esta acontece em etapas, para Vigotski (2007) também o ensino pode gerar desenvolvimento, e sua preocupação não é em descrever etapas do desenvolvimento da criança, mas em compreender processos e relações.

O terceiro autor é Willhelm Reich, que tem importante contribuição para a psicologia ao trazer o conceito de unidade funcional entre o corpo e a mente, sendo um autor ainda pouco conhecido no campo da educação.

O quarto e último autor é Martin Buber, que, diferentemente dos outros três, vem da filosofia, mais especificamente da filosofia do diálogo, e tem influência sobre as psicoterapias de base fenomenológica e humanista; desde os anos 1950, ele tem trazido contribuições também para a área da educação.

O objetivo deste artigo é explicitar os principais conceitos das teorias de cada um desses pensadores e como suas ideias chegaram ao campo da educação, buscando com isso elementos que ajudem na compreensão da relação professor-aluno em sala de aula.

\section{Jean Piaget: como o ser humano conhece}

Orientado por uma perspectiva cognitivista-interacionista ancorada nos mecanismos de modelo biológico, Piaget situa seu projeto em dois planos distintos: a história do pensamento científico e o estudo experimental do desenvolvimento da inteligência (SOUZA; KRAMER, 1991).

A maior preocupação de Piaget foi compreender o que é o conhecimento, como o conhecimento se transforma e transforma o sujeito ao longo de sua vida (SOUZA, 1998). Recorrendo a outras áreas do conhecimento para além da filosofia, como a biologia, a matemática, a física e a linguística, ele chegou à construção da Epistemologia Genética, baseada na inteligência e na construção do conhecimento.

Sua preocupação era com a capacidade do conhecimento humano e com seu desenvolvimento. "E, como na sua visão, a criança é o ser que mais notoriamente constrói conhecimento, suas pesquisas e observações voltaram-se para a construção e a aquisição de conhecimentos pelos homens na idade infantil e na adolescência" (PÁDUA, 2009, p. 22).

Para Piaget (1959), o desenvolvimento da inteligência é a condição para que os seres humanos construam conhecimento sobre o meio, sendo definida como função e como estrutura. Como função, a inteligência deve ser compreendida como adaptação, ou seja, ela tem como finalidade a sobrevivência do sujeito no meio em que está inserido, modificando-o se necessário ou se modificando para melhor se adaptar a esse meio. Do ponto de vista estrutural, a inteligência é uma organização de processos que está associada a níveis de conhecimento e, sendo assim, o desenvolvimento dela não se dá por acúmulos de informações, mas sobretudo por uma reorganização dessa troca de inteligências (PÁDUA, 2009). Esse processo de adaptação ao meio se realiza mediante os processos de assimilação e acomodação.

O conhecimento, segundo Piaget (1959), não está no sujeito nem no objeto, mas é decorrente das interações entre os dois.

A relação cognitiva sujeito/objeto trata de processos de assimilação [ou seja], quando uma pessoa entra em contato com o objeto de conhecimento, ela retira desse objeto algumas informações e as retém, e são essas informações, e não todas, e nem outras que são retidas porque existe uma organização interna a partir de estruturas já existentes (PÁDUA, 2009, p. 24).

Para Piaget (1996, p. 309), “a assimilação e a acomodação são [...] os dois pólos de uma interação entre o organismo e o meio, a qual é a condição de todo funcionamento biológico e intelectual". Nessa interação com o meio, a organização que a pessoa tem para conhecer o mundo - seus esquemas mentais - é capaz de se modificar para atender às necessidades do objeto, e a esse processo Piaget (1996) chamou de acomodação.

O sujeito, ao entrar em contato com um objeto desconhecido, pode entrar em conflito, ou seja, no processo de assimilação, o que é novo, às vezes, oferece certas resistências ao conhecimento e para conhecer esse objeto o sujeito precisa modificar suas estruturas mentais e acomodá-las. A esse processo de busca do equilíbrio dessas modificações que Piaget denominou equilibração (PÁDUA, 2009, p. 25).

O desenvolvimento é, então, para Piaget, um processo dialético que envolve equilíbrio - desequilíbrio - reequilíbrio, sugerindo a ideia de algo móvel e dinâmico.

Piaget contestava tanto os racionalistas - que defendiam que o conhecimento é algo que pertence ao sujeito mesmo antes de este estabelecer qualquer contato com o mundo externo - como os empiristas - que afirmam que o conhecimento está contido nos objetos e, portanto, os sujeitos seriam receptores passivos de um conhecimento que preexiste à sua própria experiência (SOUZA, 1998). Ao discordar dessas duas posições, Piaget desenvolve a ideia de que o conhecimento é construído na relação entre o sujeito e os objetos do mundo externo.

Para a epistemologia genética, a construção dos conhecimentos não se dá de forma linear, mas através de saltos e rupturas e, por isso, ela define quatro estágios de desenvolvimento, sugerindo que existe uma sequência e uma sucessão no desenvolvimento da inteligência.

Embora Piaget nunca tenha proposto um método de ensino, suas ideias chegaram ao campo da educação no Brasil nos anos 1970, pelas mãos de professores, psicólogos, pedagogos e secretarias de educação, preocupados em solucionar problemas de aprendizagem e desenvolvimento das crianças, muitas vezes causando a distorção de sua teoria. O construtivismo alterou o espaço escolar e trouxe uma nova organização para as escolas tradicionais, incluindo a relação professor-aluno. 
A perspectiva construtivista de Piaget desloca a ênfase do professor para a criança, atribuindo a ela um papel ativo, vendo-a como responsável por seu processo de aquisição de conhecimento. Sendo assim, a espontaneidade, a autonomia e a criatividade da criança ganham lugar de destaque no processo educativo. Nesse contexto, o professor tende a assumir um papel desafiador, provocando desequilíbrios para que a criança seja estimulada a descobertas e à construção do conhecimento.

O trabalho de Piaget recebeu críticas por dar ênfase ao modelo biológico de adaptação ao meio, submetendo os aspectos socioculturais a um plano secundário na constituição do sujeito. Um desses críticos foi Vigotski.

\section{Lev Vigotski: como o ser humano cria}

A obra de Vigotski sustenta-se no materialismo histórico e dialético - concepção filosófica que compreende que todos os fenômenos devem ser estudados como processos em movimento e em mudança - e busca compreender o psiquismo e a consciência, a arte e a imaginação no contexto da produção humana (KRAMER, 2002).

Formulada por Vigotski, a psicologia histórico-cultural nasce em um contexto de questionamentos: tanto a psicologia objetiva, representada pelo behaviorismo de Skinner, quanto a psicologia subjetiva da Gestalt e a psicologia construtivista de Piaget apresentavam-se como modelos representativos da psicologia humana. Para o psicólogo russo, nenhuma dessas escolas da psicologia fornecia bases consistentes para o estabelecimento de uma teoria unificada dos processos psíquicos humanos. Para a superação desta crise na psicologia, ele considerou necessário formular um novo método, capaz de conciliar a cientificidade na abordagem da vida psíquica, sem o reducionismo das abordagens positivistas ou naturalistas dominantes. Rompendo tanto com o racionalismo idealista quanto com o empirismo, Vigotski propõe uma nova psicologia, que entende o ser humano como uma unidade, reconhecendo, da mesma forma, o aparato biológico e a cultura e compreendendo o desenvolvimento humano à luz de seus determinantes econômicos e socioculturais (CASTRO, 2015).

Para a psicologia histórico-cultural, a personalidade não é algo inato nem o sujeito se constitui apenas do meio. O ser humano interage com o meio - com as pessoas e com os objetos da cultura -, numa relação dialética entre elementos internos e externos. Assim, enquanto o sujeito age sobre o meio, ele o modifica ao mesmo tempo em que é modificado pelo que o cerca.

Neste sentido, na constituição do sujeito não há prevalência do fator biológico, nem do fator social, nem da simples relação entre ambos, mas de um processo de construção histórico-cultural do contexto social e do meio, pela própria atividade do sujeito. Diante disso, para estudar o seu processo de desenvolvimento não se deve partir de seu pensamento, mas sim da atividade de sua vida real (CASTRO, 2015). Tomando os indivíduos como sujeitos sociais, Vigotski ressalta o papel mediador e regulador da linguagem, como o instrumento que permite o contato com o mundo exterior e consigo mesmo, exercendo uma função crucial no processo de formação da consciência. Os estudos de Vigotski representam uma ruptura com o dualismo da psicologia, uma vez que ele se opunha à oposição entre sentimento e razão, entre intelecto e afetividade, afastando-se tanto do enfoque idealista quanto da concepção de Piaget.

Vigotski (2007) afirma que o sujeito se desenvolve porque aprende. A aprendizagem, então, promove o desenvolvimento. O desenvolvimento, para o autor, deve ser olhado como o que está em processo, como possibilidade de acontecer. E, para que este desenvolvimento aconteça, ele deve se dar na interação com o outro. Nesse sentido, "o que a criança consegue fazer com ajuda dos outros poderia ser, de alguma maneira, muito mais indicativo de seu desenvolvimento mental do que o que consegue fazer sozinha" (VIGOTSKI, 2007, p. 96). Sobre esta relação entre o desenvolvimento e a atividade do sujeito, Vigotski elabora o conceito de Zona de Desenvolvimento Iminente, que é

[...] a distância entre o nível do desenvolvimento atual da criança, que é definido com ajuda de questões que a criança resolve sozinha, e o nível do desenvolvimento possível da criança, que é definido com ajuda de problemas que a criança resolve sob orientação dos adultos e em colaboração com companheiros mais inteligentes (PRESTES, 2010, p. 173).

Neste texto, faço a opção por chamar de Zona de Desenvolvimento Iminente, sem querer entrar na polêmica que acompanha essa discussão entre chamar de Proximal ou Iminente, mas por ser esse o termo que vem sendo empregado nos últimos encontros internacionais sobre Vigotski.

Sendo assim, se a situação de ensino é adequadamente organizada, o aprendizado não só deriva em desenvolvimento, como também é capaz de desencadear vários processos, o que não aconteceria espontaneamente (KRAMER, 2002). Para Vigotski (2007), o bom aprendizado é somente aquele que se adianta ao desenvolvimento. É nesse sentido que o autor aborda a forte relação entre os conhecimentos científicos e os conhecimentos espontâneos, que surgem de formas diferentes e se movimentam em direções contrárias. Suas concepções sobre o processo de formação dos conceitos científicos remetem à importância da instituição escolar nas sociedades letradas e ao papel do professor como mediador nesse processo, em que a intervenção pedagógica provoca avanços que não ocorreriam espontaneamente (LA TAILLE; OLIVEIRA; DANTAS, 1982). A qualidade do desenvolvimento psicológico não é inerente a qualquer ensino, mas depende de como ele é organizado.

Segundo o autor, a atividade de brincar cria uma zona de desenvolvimento iminente na criança. Na brincadeira, "a criança sempre se comporta além do comportamento habitual de sua idade, além de seu comportamento diário; no brinquedo, é como se ela fosse maior do que é na realidade" (VIGOTSKI, 2007, p. 122). Agir em situações imaginárias, criar intenções voluntárias e formular planos da vida real fazem do brincar o mais alto nível de 
desenvolvimento na infância. Nessa perspectiva, Vigotski (2007, p. 122) afirma que "a criança desenvolve-se, essencialmente, através da atividade de brinquedo".

Para Vigotski, a fantasia é vitalmente necessária e parte da experiência acumulada pelo ser humano; logo, quanto mais rica é a experiência, mais rica é a fantasia. Mais do que isso: a fantasia amplia a experiência e expande o sujeito para além do circunstancial e do imediato (KRAMER, 2002).

Das análises de Vigotski, emerge a concepção de que a criança não é um adulto incompleto, nem se constitui em uma sequência de etapas; ela é sujeito social e histórico, desenvolvendo-se como pessoa real, cidadã. E o professor não é um ser estático, completo; ele se constrói, cresce, muda (KRAMER, 2002).

$\mathrm{Se}$, para a psicologia histórico-cultural, o bom aprendizado é aquele que se adianta ao desenvolvimento, cabe ao professor organizar o conteúdo escolar e as estratégias de ensino, considerando o desenvolvimento real e o desenvolvimento iminente do aluno. Pensar o professor como o parceiro que colabora para o desenvolvimento do aluno, como aquele que o auxilia naquilo que ele ainda não consegue fazer sozinho, é uma das consequências da teoria de Vigotski para pensar a relação professor-aluno.

Portanto, o professor é aquele que dirige o processo de ensino e aprendizagem do aluno, sugerindo uma assimetria entre professor e aluno, que deve ser superada ao final do processo. O professor é, ainda, aquele que intervém de forma consciente e intencional, enfatizando o trabalho com a linguagem e a criação, visando garantir a apropriação do patrimônio cultural humano pelo aluno.

\section{Wilhelm Reich: como o ser humano se expressa}

Reich, nascido na Áustria em 1897, não foi um pensador com atuação restrita aos limites de uma única área do conhecimento. Acreditando na possibilidade de maior felicidade humana, participou de diversos movimentos de seu tempo que pudessem contribuir para a realização desse objetivo. Um desses movimentos foi a psicanálise de Freud, que nascia no início do século XX e que consistia em um processo de investigação sobre os processos mentais, cujo método básico era o manejo da transferência e a análise da resistência. Freud, com suas postulações sobre o inconsciente, estabelecia um diálogo crítico com correntes da psicologia, que tinham como objeto de estudo a consciência entendida em uma perspectiva neurológica (RAKNES, 1988).

Reich, ainda na faculdade de medicina, participou do "Seminário de sexologia" criado por alguns estudantes insatisfeitos com a falta de referência a este tema na formação dos médicos. Pertenceu à Sociedade Psicanalítica de Viena, onde foi aluno de Freud, e seu principal interesse voltou-se para a técnica terapêutica, levando-o à criação de uma organização em que analistas com pouca experiência pudessem expor os casos clínicos e discutir suas dificuldades técnicas.
A experiência profissional de maior influência nos rumos do trabalho de Reich aconteceu na Clínica Psicanalítica de Viena, onde ele fez contato com a população que enfrentava dificuldades econômicas, uma vez que era oferecido atendimento gratuito às pessoas que não tinham como pagar por um tratamento nas clínicas particulares. Essa experiência influenciou todo o trabalho futuro de Reich, que se filiou ao Partido Comunista e estudou o marxismo, chegando a publicar um manifesto intitulado "Materialismo dialético e psicanálise", onde situava seu ponto de vista: o marxismo tentava libertar a sociedade da economia burguesa, da mesma forma que a psicanálise procurava libertar a sociedade da moral burguesa. Pode-se afirmar que as ideias reichianas que vão emergindo dentro da psicanálise trazem uma visão basicamente otimista frente às possibilidades de vida do homem. Ou seja, o problema da infelicidade não estava no próprio sujeito ou na relação dele com a civilização - como defendia a psicanálise da época -, mas vinha de fora, a partir de determinadas condições sociais, características de uma cultura patriarcal e capitalista.

Dirigindo o Seminário para a Terapia Psicanalítica de Viena, Reich propõe uma maior atenção à questão da resistência do paciente ao tratamento, passando a dedicar um especial interesse à forma como cada paciente resistia à terapia. Nas palavras de Reich (1989, p. 151):

Como a maioria dos pacientes era incapaz de seguir a regra básica da psicanálise, isto é, dizer tudo quanto vinha à mente, deixei de insistir nisso. No seu lugar, usei como meus pontos de ataque não só o que o paciente comunicava, mas tudo quanto oferecia, particularmente a maneira como fazia as suas comunicações, ou permanecia em silêncio. Mesmo em silêncio, os pacientes se revelavam, expressando algo que podia ser gradualmente esclarecido e dominado. Lado a lado com o 'que' da velha teoria freudiana, coloquei o 'como', isto é, a forma do comportamento e das comunicações era muito mais importante do que o que o paciente dizia ao analista. As palavras podem mentir. A expressão nunca mente. Embora as pessoas não tenham consciência disso, a expressão é a manifestação imediata do caráter.

Caráter, para Reich, indica a existência de uma estrutura resultante de um processo de construção histórica, nunca algo meramente inato. Assim, as defesas utilizadas como forma de adaptação ao meio são incorporadas permanentemente pelo indivíduo e resultam numa estrutura crônica, repetitiva, baseada em mecanismos de ação e proteção automáticos - o que acaba por limitar as possibilidades de mobilidade individual.

Para a teoria reichiana, o comportamento é sempre uma manifestação muscular: como a pessoa fala, como gesticula, como caminha, o que revela sempre um comprometimento muscular, e isto significa que o caráter é ligado ao corpo, é ligado à função muscular do corpo.

O ser humano vive com e por meio dos músculos, e as correlações entre psiquismo e distúrbios neuromusculares o confirmam: quando a agressividade (do latim ad-gredir = encostar, entrar em contato), que é fundamental para o desenvolvimento humano, é frustrada, isto é, se a possibilidade de expressão é reprimida (por fatores cul- 
turais, preconceitos educacionais, ambiente estressante, etc.), ela permanece emocional e energeticamente retida nos músculos e encontra, como compensação substitutiva ou função reativa, a necessidade de descarregar-se psicologicamente (NAVARRO, 1990).

Para Reich (1989), quando o fluxo de energia corporal não transita pelo corpo de forma harmônica, diz-se que esse corpo está bloqueado. A “couraça muscular” bloqueia o indivíduo. Ela funciona como um mecanismo de defesa, cuja função é impedir que o indivíduo tenha contato com experiências emocionais que lhe são ameaçadoras e dolorosas. Couraça muscular é o resultado crônico de choque entre as exigências pulsionais - relativas à sexualidade $-\mathrm{e}$ o mundo externo que frustra essas exigências. A couraça muscular funciona como uma forma de o indivíduo se proteger das situações desagradáveis e desconfortáveis vindas da relação com o meio e com o viver em sociedade. E, normalmente, a emoção que faz com que o indivíduo tenha necessidade de se defender é o medo.

Expressões como "sente-se direito", "feche as pernas", "não chore", "comporte-se", "fique quieto", "endireite as costas", "não se suje", "tire a mão daí" são muito repetidas por educadores nas escolas. Junto com as palavras vêm a voz e a feição alteradas, "levando a criança a nada fazer a não ser ficar parada, imobilizada, educando-se para o não-movimento, substituindo seu comportamento espontâneo e dinâmico pela obediência quase sempre sinônimo de inibição, sobretudo da atividade muscular" (MATTHIESEN, 2005, p. 200) - especialmente quando essas palavras são ditas por pessoas com quem as crianças têm laços afetivos. A isso Reich (1989) denominou técnica muscular de encouraçamento, que busca, a todo custo, instaurar a ordem a partir da justificativa de aquisição do conhecimento. Sob a ameaça constante de serem acusadas de mal-educadas, as crianças comprometem seu funcionamento prendendo a respiração, contraem-se para bloquear todo e qualquer movimento, reprimem o choro, arcando com as consequências de um processo em que o combate à falta de educação evidencia justamente o oposto: os excessos de uma educação que inibe não só o corpo, mas o pensamento e a ação, uma vez que essas instâncias não são separadas.

Com essa concepção, Reich questiona o paradigma moderno que apresenta a racionalidade como conceito central na produção do conhecimento, relegando a um segundo plano outras formas de conhecer o mundo, como as sensações, as emoções e os afetos.

Diversas pesquisas acadêmicas vêm apontando como as práticas pedagógicas em creches, pré-escolas e escolas expressam claramente que a instituição escolar, historicamente, não tem pelo corpo o mesmo apreço que tem pela mente e, em seu cotidiano, separam o corpo da mente, fragmentam o pensar e o sentir. As disciplinas escolares, como as conhecemos tradicionalmente, apresentam uma visão fragmentada de um conhecimento especializado, em que não é valorizado o que o aluno pensa e, menos ainda, o que ele sente. Seu corpo, suas emoções, sentimentos, descobertas, deslumbramentos ou angústias pouco têm lugar na vida escolar (PEREIRA, 2008).

Fractal, Rev. Psicol., v. 33 - n. 2, p. 91-99, 2021
Reich postulou a unidade funcional entre o psíquico e o somático, concluindo que a mesma energia alimenta esses dois aspectos, gerando a relação mútua entre atitudes corporais e atitudes psíquicas. Psique e corpo são faces de uma totalidade.

Pensar a relação professor-aluno apoiada nas contribuições de Reich é levar em consideração a complexidade do ser humano; é compreender que o espaço institucional da escola é atravessado pela totalidade que constitui adultos e crianças em sua convivência diária: suas sensações, seus sentimentos e pensamentos. A comunicação que se estabelece sem palavras - a expressão facial, os silêncios, os gestos - é um importante aspecto para essa relação, ainda pouco valorizado nos currículos e nas práticas pedagógicas.

\section{Martin Buber - o que é o ser humano}

Nascido em Viena, em 1878, Buber foi um dos mais importantes filósofos do século XX, e ainda hoje contribui para a reflexão sobre o sujeito contemporâneo. Foi incluído por Michael Löwy (1989) como socialista utópico, no grupo formado por autores alemães judeus - como Walter Benjamin, Adorno e Hanna Arendt, entre outros - que atravessaram o mesmo momento histórico no qual se acelera e se confirma a desumanização acarretada pela crescente modernidade. Em sua mais conhecida obra, Eu e Tu, Buber (1923/2003a) insistia em que o princípio dialógico não era uma concepção filosófica, mas uma realidade além do alcance da linguagem discursiva. Para ele, o que distingue o ser humano não é a razão, mas a capacidade de relação.

Para a filosofia do diálogo concebida por Buber (2003a), a palavra fundamenta a existência humana e a linguagem se manifesta diante de uma dupla atitude do ser humano frente ao mundo, por meio das palavras-princípio "Eu-Tu" e "Eu-Isso". A palavra princípio Eu-Tu fundamenta a existência em sua total atualidade, no evento da relação, da reciprocidade, da totalidade do ser, da presença; a palavra princípio Eu-Isso fundamenta a existência em sua parcialidade ou limitação, no fato da experiência, do eu egocêntrico, do objeto.

$\mathrm{Na}$ relação Eu-Tu, existe a totalidade do ser; na experiência do Eu-Isso o ser não pode ser total, ele é fragmentado. O conceito de relação é total, é o entre, a presença, a existência, a essência, o inteiro, o concreto, é sinônimo de reciprocidade. Já o conceito de experiência é fragmentado, parcial, objeto, não permite a relação, apenas o relacionamento. Buber (2003a) entende por totalidade a inteireza do ser humano; sua presença em corpo, mente e espírito; com responsabilidade para com o outro.

Buber (2003a) adverte que as duas atitudes (Eu-Tu e Eu-Isso) não podem ser confundidas nem tomadas de forma maniqueísta, cada uma tem a sua função; o problema é o predomínio crescente do relacionamento Eu-Isso em detrimento da relação Eu-Tu, que se reflete, por exemplo, na modernidade, com o crescimento descontrolado da racionalidade tecnocientífica. 
A visão de Buber sobre a educação vai ao encontro da sua filosofia do diálogo e se apresenta em "Discursos sobre Educación", conjunto de textos sobre educação que se encontra no livro El caminho do ser humano y otros escritos (BUBER, 2003b). No texto, o autor trata do desenvolvimento das forças criadoras das crianças. Lembra que o gênero humano nasce a cada instante e que cada nascimento é um momento de criação. Cada um, ainda que se entrelace a um acúmulo de antecedentes históricos, é único, e cada nascimento é um acontecimento singular.

Buber fala do instinto criador, não como ocupação, mas como querer fazer coisas, ser sujeito do processo, construir, criar. No entanto, o filósofo se opunha a uma educação baseada somente na formação do impulso criador, que levaria, em última instância, ao isolamento do ser humano, uma vez que esse impulso sozinho não pode conduzir à participação nem à reciprocidade. Para isso, é necessária a presença do outro, o educador.

Por isso, Buber criticava a educação nova, centrada só na criatividade do aluno - apesar de reconhecer suas grandes contribuições -, defendendo que, para que as forças criativas da criança se manifestem, há a necessidade também das forças educativas. Buber não compartilhava da concepção da educação nova sobre o papel do professor. Para ele, o professor da educação tradicional representava o mundo histórico para o aluno (relação mestre-discípulo). Apesar de considerar certos aspectos da educação nova positivos, em relação à antiga, não aceitava a ideia de deixar a criança se desenvolver de forma espontânea. $\mathrm{O}$ papel do professor não seria apenas o de ajudar no desenvolvimento dessa espontaneidade, mas sim selecionar o tipo de experiência desejável. Para Buber, a criança e o professor estão juntos no centro do processo educativo (HILLIARD, 1973).

A educação para Buber (2008) é a preparação para o sentido de comunidade e, sendo assim, ela não pode ser teórica, ela só pode ocorrer através da comunidade, daquilo que os sujeitos experimentam juntos. Para isso, é preciso saber o que educa e quem educa. "O que educa é, em última análise, o espontâneo" (BUBER, 2008, p. 90). Com isso, o autor, não está fazendo uma defesa do espontaneísmo, uma vez que o oposto de espontâneo nesse caso não seria o controle ou o direcionamento, mas sim a omissão. Ele acredita que o professor educa com sua presença, com sua existência pessoal, com seu exemplo, com suas perguntas e suas opiniões, e influencia o aluno quando as relações entre ambos são espontâneas a ponto de o educando não saber nem perceber que está sendo educado.

Nesse sentido, o educador se distingue das outras pessoas que compõem o mundo do educando pela vontade que orienta sua ação intencional de participar desse processo e, por isso, a educação é assim compreendida como responsabilidade com o outro, que é um elemento daquilo que se chama relação e que só pode acontecer onde há abertura e confiança.

A confiança é o que permite a ruptura da incomunicação, e ela só é obtida na medida em que se participa imediatamente da vida dos alunos e se assume a responsabilidade que daí deriva. A partir da confiança, o aluno sente-se incluído numa relação dialógica e aceita o educador como pessoa, acontecendo o que Buber (2003b) chamou de encontro pedagógico, que se diferencia da intenção pedagógica.

Intenção pedagógica e encontro pedagógico são dois termos utilizados por Buber que dizem respeito à ação do professor na sua prática e à relação com os alunos. Enquanto a intenção pedagógica se refere ao esforço do educador para obter resultados, o encontro pedagógico envolve a educação do caráter e diz respeito a uma postura do professor diante das necessidades concretas do aluno, ajudando-o a posicionar-se diante do mundo. Implica responder com responsabilidade diante da situação concreta na qual vive o aluno.

Buber trata, ainda, da liberdade como condição para a educação, mas não como sua tarefa fundamental. A educação pressupõe que haja liberdade de pensamento, de opinião e ação, mas é uma possibilidade e não finalidade. Em uma perspectiva buberiana, liberdade em educação é possibilidade de comunhão, comunhão com a natureza e os seres humanos. Quando não há comunhão o que se encontra é a coação, humilhação e rebeldia. A liberdade é imprescindível à vida humanizada, mas ela em si mesma não humaniza, ela é ponto de partida.

O diálogo é perpassado pela responsabilidade que deve ser "personal e intransferible" (BUBER, 2003b, p. 16). A responsabilidade, para Buber, só existe onde existe o responder verdadeiro diante dos acontecimentos do cotidiano, sejam eles grandes ou pequenos. Podemos responder ao que nos acontece, ao que sentimos, vemos e ouvimos com o silêncio ou nos escondermos no hábito ou na couraça, que tem a tarefa de repelir signos.

Buber ajuda a pensar as relações entre adultos, jovens e crianças na vida e na escola, onde, muitas vezes, a marca das interações é a invisibilidade (KRAMER, 2009), além de oferecer elementos para questionarmos a qualidade da presença dos professores na vida dos alunos.

O conceito de diálogo, responsabilidade e encontro pedagógico é central para pensar as relações na educação. Para Buber, o diálogo é o que constitui o ser humano, implicando a aceitação do outro na sua inteireza - com seus sentimentos, sua presença, seu corpo, seu espírito e sua responsabilidade.

O conceito de diálogo de Buber influenciou a teoria de Mikhail Bakhtin, como citado por seus biógrafos, e a obra de Paulo Freire, que, em Pedagogia do oprimido (FREI$\mathrm{RE}, 2011)$, traz uma nota de rodapé fazendo referência ao filósofo. Aceitar implica ver o outro não como objeto, mas a partir de conhecimento sobre o Eu e o Outro. 
Para Buber, a relação educativa é a relação dialógica por excelência, já que a base da relação professor-aluno é a reciprocidade. No entanto, para o filósofo, essa relação é marcada por uma assimetria, assim como defende Vigotski (2009), uma vez que o educador experimenta como o aluno é educado; o aluno, pelo contrário, não pode experimentar como o educador o educa. $\mathrm{O}$ educador se encontra nos dois lados da situação comum; o aluno encontra-se apenas em um.

O diálogo e a presença, para Buber, implicam responsabilidade e, no âmbito da relação professor-aluno, se traduzem na resposta do professor, na sua ação, no seu ato ético diante das situações que atravessam as práticas nas escolas.

\section{As relações entre adultos, jovens e crianças em instituições educativas}

Os autores trazidos aqui são representantes de saberes construídos ao longo do século XX que dialogaram com as questões emergentes de sua época. Suas teorias cruzaram o mundo e influenciaram, em maior ou menor grau, discursos produzidos sobre o que é o ser humano, sobre como ele conhece, como cria, como se expressa, adentrando o mundo da escola e influenciando as relações e as práticas que se estabelecem nesse espaço.

A observação das relações entre adultos e crianças nas instituições educativas evidencia, muitas vezes, um contexto de pouca liberdade, com uma experiência de vida árida, pouco relacional (KRAMER, 2009). As crianças, muitas vezes, são submetidas ao controle dos corpos, ao silenciamento dos seus desejos, à moralização das relações.

$\mathrm{Na}$ escola, ainda no século XXI, circulam diversos discursos, por vezes até contraditórios, que revelam as muitas influências científicas e filosóficas que foram constituindo essa instituição desde seu surgimento. Dentre esses discursos está o da psicologia, que sempre exerceu forte influência na pedagogia, sustentada por teorias diversas ao longo de todo esse tempo, que chegaram ao campo educacional com apropriações e deturpações que colaboraram com a ideologia de cada momento histórico.

Patto (1999) aponta como a psicologia, desde seu início, teve seu discurso apropriado para justificar uma sociedade que tem em sua estrutura uma desigualdade de classes. A psicologia experimental, a psicologia do desenvolvimento e a psicanálise serviram, em momentos distintos da história da educação brasileira, para dar sustentação a certas concepções - meritocracia, carência cultural, adaptação, inteligência, ambiente sociofamiliar desajustado, criança-problema - que, em última instância, estavam a serviço de um discurso ideológico que explicava cientificamente o fracasso escolar, responsabilizando o aluno, o professor, o ambiente ou a família, deixando de tocar no cerne da questão: a desigualdade social.

As contribuições da psicologia, assim como de outras áreas do saber, para a educação devem caminhar no sentido de ajudar a compreender as relações que se estabelecem no interior das instituições educativas, em que, muitas vezes, os elos entre as pessoas estão desumanizados e marcados por atitudes de confronto, intolerância e rejeição (KRAMER, 2013). Alunos e professores são, frequentemente, vistos de forma fragmentada: ora valorizando aspectos cognitivos, ora questões morais, ou ainda só como corpos a serem contidos e docilizados. Adultos com medo de exercer autoridade e construir limites; crianças e jovens instáveis e inseguros.

Transformar esse outro de quem eu falo naquele com quem eu falo é o desafio da educação em qualquer segmento. Ver, escutar, aceitar, acolher, ter atenção e autoridade são tarefas do professor de crianças, jovens e adultos em que prevaleça a dimensão humana sobre a utilitária, em que prevaleça uma ética do cuidado com o outro.

Se a psicologia do século XX contribuiu no passado para fundamentar práticas de exclusão nas escolas, corroborando a concepção de carência cultural das classes mais empobrecidas, através de testes e laudos, a psicologia da educação pode contribuir para a desnaturalização dos conceitos (e preconceitos) que sustentam as discriminações de raça, de gênero, de classe, de religião, entre outros aspectos culturais. Pode, ainda, ser importante aliada no exercício da ética, inseparável da prática pedagógica, seja com crianças, jovens ou adultos.

Atualmente, a educação enfrenta os desafios da violência, da medicalização e da discussão de gênero, para citar alguns. Assuntos que são, muitas vezes, deslocados das escolas para as mãos de especialistas, que podem reduzi-los a questões de ordem biológica e, portanto, tratadas pela ótica do desvio e por uma visão médica. A psicologia muito tem a contribuir nesses casos, contextualizando esses fenômenos e abordando-os no interior das escolas, no âmbito das relações entre as pessoas, considerando a complexidade que envolve essa discussão.

A relação professor-aluno é constituída pelas relações entre adultos e adultos, adultos e adolescentes e adultos e crianças, situadas em determinados contextos sócio-históricos. Portanto, quando discutimos essa relação, temos que levar em conta tanto as especificidades quanto aquilo que é comum a todas elas por se tratar de vínculo entre pessoas. Temos de considerar, portanto, que essa relação se constrói em um determinado tempo e espaço, marcados por valores, ideologias, normas e discursos.

Aprendemos com Paulo Freire (2013) que a educação é concebida como prática social que tem como finalidade a formação humana. Ela pressupõe a relação dialógica e deve se dar no lugar onde se está, no cotidiano, na prática e não apenas na teoria; uma vivência concreta que se realiza nesse mundo, com fortes implicações políticas. Nesse sentido, é importante que haja mais pesquisas e estudos futuros nessa área. 


\section{Informações sobre a autora:}

Alexandra Coelho Pena

\section{(iD) https://orcid.org/0000-0003-3363-6059}

(9) http://lattes.cnpq.br/3002450726771347

Graduada em Psicologia pela USU, especialista em Educação Infantil pela PUC-Rio, mestre pelo Instituto de Psicologia da UFRJ e doutora em Educação pela PUC-Rio. Pós-doutorado no Departamento de Educação da PUC-Rio. Coordenadora do Grupo de Pesquisa INFOC (Infância, Formação e Cultura). Professora do Departamento de Educação da PUC-Rio. Coordenadora e professora do Curso de Especialização em Educação Infantil: perspectivas de trabalho em creches e pré-escolas, da PUC-Rio. Coordenadora e professora do Curso de Extensão "A creche e o trabalho cotidiano com crianças de 0 a 3 anos", da PUC-Rio. Tem experiência nas áreas de Educação Infantil, Formação de Professores, Histórias de Vida e Pesquisa.

\section{Como citar este artigo:}

\section{ABNT}

PENA, Alexandra Coelho. Contribuições da psicologia para a relação professor-aluno. Fractal: Revista de Psicologia, Niterói, v. 33, n. 2, p. 91-99, maio/ago. 2021. https://doi.org/10.22409/19840292/v33i2/5792

\section{APA}

Pena, A. C. (2021, Maio/Agosto). Contribuições da psicologia para a relação professor-aluno. Fractal: Revista de Psicologia, 33(2), 91-99. doi: https://doi.org/10.22409/1984-0292/v33i2/5792

\section{Copyright:}

Copyright (C) 2021 Pena, A. C. Este é um artigo em acesso aberto distribuído nos termos da Licença Creative Commons Atribuição que permite o uso irrestrito, a distribuição e reprodução em qualquer meio desde que o artigo original seja devidamente citado.

Copyright (C) 2021 Pena, A. C. This is an Open Access article distributed under the terms of the Creative Commons Attribution License, which permits unrestricted use, distribution, and reproduction in any medium, provided the original article is properly cited.

\section{Referências}

BUBER, Martin. Eu e Tu (1923). São Paulo: Centauro, 2003a.

BUBER, Martin. El camino del ser humano y otros escritos. Madrid: Fundación Emmanuel Mounier, 2003b.

BUBER, Martin. Sobre comunidade. São Paulo: Perspectiva, 2008.

CASTRO, Liana Garcia. Espaços, práticas e interações na educação infantil: o que dizem as crianças. 2015. $135 \mathrm{f}$. Dissertação (Mestrado em Educação) - Departamento de Educação, Centro de Teologia e Ciências Humanas, Pontifícia Universidade Católica do Rio de Janeiro, Rio de Janeiro, 2015. Disponível em: https:/grupoinfoc.com.br/publicacoes/ mestrado/m03.pdf. Acesso em: 20 jan. 2017.

FREIRE, Paulo. Pedagogia do oprimido. 50. ed. São Paulo: Paz e Terra, 2011.

FREIRE, Paulo. Pedagogia da autonomia: saberes necessários à prática educativa. São Paulo: Paz e Terra, 2013.

HILLIARD, Frederick Hadaway. A Re-Examination of Buber's Address on Education. British Journal of Educational Studies, v. 21, n. 1, p. 40-49, 1973. https://doi.org/10.1080/00071005.1 973.9973364
KRAMER, Sônia. Por entre as pedras: arma e sonho na escola. São Paulo: Ática, 2002.

KRAMER, Sônia (Org.). Retratos de um desafio: crianças e adultos na educação infantil. São Paulo: Ática, 2009.

KRAMER, Sônia. Contribuições de Martin Buber para a reflexão sobre/do homem contemporâneo. In: LEWIN, Helena (Org.). Judaísmo e cultura: fronteiras em movimento. Rio de Janeiro: Imprimatur, 2013. p. 581-589.

LA TAILLE, Yves de; OLIVEIRA, Marta Kohl de; DANTAS, Heloysa. Piaget, Vigotski e Wallon: teorias psicogenéticas em discussão. São Paulo: Summus, 1982.

LÖWY, Michael. Redenção e utopia: o judaísmo libertário na Europa Central. São Paulo: Cia das Letras, 1989.

MATTHIESEN, Sara Quenzer. A educação em Wilhelm Reich: da psicanálise à pedagogia econômico-sexual. São Paulo: Unesp, 2005.

NAVARRO, Federico. A sistemática, a semiologia e a semântica da vegetoterapia caracteronalítica. INSTITUTO DE ORGONOMIA OLA RAKNES (Org.). Revista Energia, caráter e sociedade. Rio de Janeiro: Instituto de Orgonomia Ola Raknes, 1990, p. 24-33.

PÁDUA, Gelson Luiz Daldegan de. A epistemologia genética de Jean Piaget. Revista FACEVV, v. 1, n. 2, p. 22-35, 2009. Disponível em: https://edisciplinas.usp.br/pluginfile. php/4627078/mod resource/content/1/Artigo A\%20 epistemologia $\% 20$ gen $\%$ C 3\%A 9 tica $\% 20$ de $\% 20$ Jean $\% 20$ Piaget.pdf. Acesso em: 22 jan. 2017.

PATTO, Maria Helena de Souza. A produção do fracasso escolar: histórias de submissão e rebeldia. São Paulo: Casa do Psicólogo, 1999.

PEREIRA, Lucia Helena Pena. O ritmo da vida: corporeidade, auto-expressão e desenvolvimento humano. In: CHAGAS, Marly; OLIVEIRA, Humberto (Org.). Corpo expressivo $e$ construção de sentidos. Rio de Janeiro: Mauad X/Bapera, 2008. p. 129-148.

PIAGET, Jean. A linguagem e o pensamento da criança. Rio de Janeiro: Fundo de Cultura, 1959.

PIAGET, Jean. Biologia e conhecimento: ensaio sobre as relações entre as regulações orgânicas e os processos cognoscitivos. Petrópolis: Vozes, 1996.

PRESTES, Zoia Ribeiro. Quando não é quase a mesma coisa: análise de traduções de Lev Semionovitch Vigotski no Brasil: repercussões no campo educacional. 2010. 295 f. Tese (Doutorado em Educação) - Universidade de Brasília, Brasília, 2010. Disponível em: https://repositorio.unb.br/ handle/10482/9123. Acesso em: 21 jan. 2017.

RAKNES, Ola. Wilhelm Reich e a orgonomia. São Paulo: Summus, 1988.

REICH. Wilhelm. Análise do caráter. São Paulo: Martins Fontes, 1989.

SOUZA, Solange Jobim e. Construtivismo e Experiência. Rio de Janeiro: [s.n.], 1998. Mimeografado.

SOUZA, Solange Jobim e; KRAMER Sônia. O debate Piaget/ Vigotsky e as políticas educacionais. Cadernos de Pesquisa, São Paulo, n. 77, p. 69-80, maio 1991. Disponível em: http:// publicacoes.fcc.org.br/index.php/cp/article/view/1044. Acesso em: 19 jan. 2017.

Fractal, Rev. Psicol., v. 33 - n. 2, p. 91-99, 2021 
VIGOTSKI, Lev Semionovitch. A formação social da mente. 7. ed. São Paulo: Martins Fontes, 2007.

VIGOTSKI, Lev Semionovitch. Imaginação e criação na infância: ensaio psicológico - livro para professores. Tradução de Zoia Prestes. São Paulo: Ática, 2009. 